\section{A Simple Method to Attach a Universal 50-bp GC-Clamp to PCR Fragments Used for Mutation Analysis by DGGE}

\section{Bert Top}

Division of Experimental Therapy, The Netherlands Cancer Institute Antonin van Leeuwenhoek Huis, $1066 \mathrm{CX}$ Amsterdam, The Netherlands
The search for sequence variations in genomic DNA becomes increasingly important in the study of inherited disease genes as well as of genes that play a role in the development of cancer. A wide variety of different methods to detect DNA sequence variations has been developed during the past few years. ${ }^{(1)}$ One of these methods, denaturing gradient gel electrophoresis (DGGE), ${ }^{(2)}$ has been shown to be very sensitive ${ }^{(3)}$ and the method of choice in studying mutations in large genes. $^{(4)}$

The detection of mutations by DGGE is based on the sequence-dependent electrophoretic mobility of doublestranded DNA fragments in a polyacrylamide gel that contains a linear denaturing gradient. A key requirement of DGGE is that the DNA fragment of interest is composed of at least two melting domains (blocks of sequence with a discrete melting temperature, or $T_{\mathrm{m}}$ ). DGGE involves electrophoresis of double-stranded DNA fragments through a polyacrylamide gel containing a linear gradient of DNA-denaturing agents (e.g., a combination of formamide and urea) at a fixed temperature (usually $60^{\circ} \mathrm{C}$ ). Initially, the migration rate of the fragment depends on its molecular weight. However, at a specific point in the gel, the combination of denaturant concentration and temperature equals the $T_{\mathrm{m}}$ of the lowest melting domain, resulting in a partially single-stranded fragment. The mobility of these branched fragments in the polyacrylamide gel is abruptly retarded. The fact that the $T_{\mathrm{m}}$ for a given domain is determined by its sequence and base composition means that two DNA fragments that differ by a single base change (and thus in $T_{\mathrm{m}}$ ) in the lowest melting domain will be separated from each other at the end of the run.

The addition of an artificial GC-rich sequence, a so-called GC-clamp, to DNA fragments has been a major improvement in DGGE methodology. ${ }^{(5,6)}$ Such a GC-clamp serves as the most stable part of the fragment and allows the detection of sequence variation in the remainder of the fragment. In general, it should be possible to detect sequence variation in any fragment attached to the GC-clamp. This GC-clamp usually consists of a stretch of 40 nucleotides of $G+C$ that is added to the DNA fragment of interest by the polymerase chain reaction (PCR), ${ }^{(7)}$ using primers in which one is extended with the GC sequence at its $5^{\prime}$ end. ${ }^{(5)}$ A practical drawback of this approach is that for each fragment to be analyzed, such a (GC-clamped) 60-mer primer has to be synthesized. To overcome the need for the synthesis of these GC-clamped primers, a simple method was developed that allows the incorporation of a universal 50-bp GC-clamp in any amplified DNA fragment during the PCR (Fig. 1).

The basic strategy of this method is a PCR carried out with three primers (referred to as A, B, and C). Primers A and B are complementary to the genomic DNA sequence to be amplified. In addition, primer B is extended at the $5^{\prime}$ end with a 15-bp GC-rich linker sequence that is not complementary to the target sequence. Primer C is a 50-bp G + C-rich primer and also contains this 15 -bp linker sequence, however, at the 3 ' end. Amplification with primers $A$ and $B$ generates DNA fragments that are extended with the 15-bp linker sequence. Since this linker sequence can serve as target sequence to which primer $\mathrm{C}$ can anneal, a second round of amplification with primers $\mathrm{A}$ and $\mathrm{C}$ will generate fragments that are further extended with $35 \mathrm{bp}$. As the linker sequence is also GC-rich, with two consecutive rounds of amplification, the target sequence originally defined by primers $A$ and $B$ will be extended with the 50-bp GC-rich sequence defined by primer $\mathrm{C}$.

The feasibility of this approach was examined on two different genomic DNA fragments: (1) an 84-bp fragment comprising the membrane-spanning region of the human c-erbB-2 proto-oncogene $^{(8)}$ and (2) a 230-bp fragment comprising exon 6 of the human nuclear phosphoprotein p53 gene. ${ }^{(9)}$ For the amplification of these fragments, primer $A$ was a 20-mer primer and primer B was a 30-mer primer composed of a 15-bp sequence complementary to the respective gene sequences and the 15 -bp linker sequence (Table 1). Optimal conditions to amplify specifically the respective genomic fragments with primers A and B were first determined (Fig. 2, lanes 1 and 3). Using this condition, the GC-clamp sequence was attached to the fragments by two consecutive rounds of PCR. The first round of amplification was carried out on $100 \mathrm{ng}$ of genomic DNA using 25 pmoles of each PCR primer A and B in a volume of $50 \mu \mathrm{l}$ and consists of $20 \mathrm{cy}$ cles. After the amplification, $1 \mu \mathrm{l}$ of this reaction mixture was then transferred to 

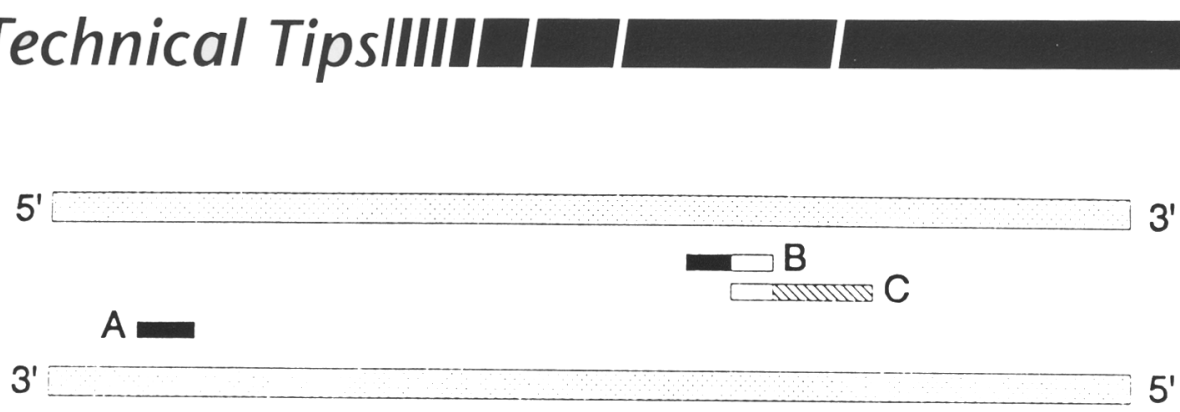

PCR

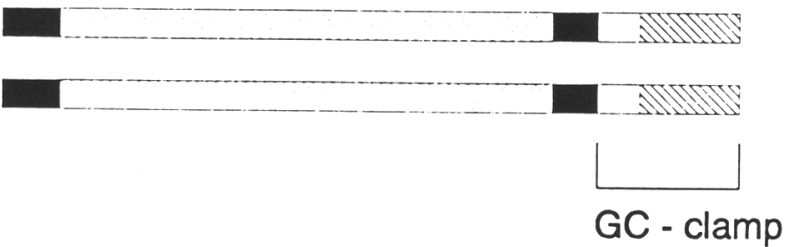

FICURE 1 Outline of the strategy to add a universal GC-clamp to DNA fragment during the PCR. Primers A and B are complementary (filled box) to the target sequence to be amplified. Primer B contains a 15-bp linker sequence at the $5^{\prime}$ end (open box). Primer $\mathrm{C}$ is a 50 -mer primer that has the 15-bp linker sequence at its $3^{\prime}$ end. The remaining $35 \mathrm{bp}$ of this primer (hatched box) are random $G$ or $C$. When the PCR is carried out with primers A and B, the linker sequence is incorporated into the amplified fragment and can serve as the specific target sequence with which primer $C$ can anneal. Subsequent amplification of the fragment with primers $A$ and $C$ then results in the amplification of PCR fragments that comprise the original genomic DNA target sequence and the additional 50-bp GC-clamp.

a second PCR reaction mixture $(50 \mu \mathrm{l}$ volume) containing 25 pmoles of each PCR primer A and C, and a further amplification was done in 35 cycles. Analysis of the generated DNA fragments on a $2.5 \%$ agarose gel demonstrates that the second round of amplification yields a single DNA fragment of the expected size (Fig. 2, lanes 2 and 4). The GC-clamped c-erbB-2 gene fragment is $134 \mathrm{bp}$ in size, whereas the GC-clamped exon 6 fragment of the p53 gene is $280 \mathrm{bp}$, indicating that the 50-bp GC-clamp is indeed attached to these fragments.

This procedure for adding GC-clamps to PCR fragments is now being used in our laboratory for the screening of p53 gene mutations by DGGE in non-small cell lung cancer (NSCLC). Prior to the screening, optimal denaturing gradient and electrophoresis conditions were determined by travel schedule experiments (not shown). Two examples of a mutation that have been found in exon 6 of the p53 gene are shown in Figure 3 (lanes 2 and 3). Genomic DNA isolated from NSCLC tissues was amplified as described above and the GC-clamped fragments were analyzed on a $30-55 \%$ denaturing gradient gel. This result proves that PCR fragments that are GC-clamped by this method are suitable for the detection of mutations.

In summary, an alternative method was developed to generate GC-clamped DNA fragments that are suitable for mutation analysis by DGGE. The advantages of this method are that the 50-bp GCrich primer has to be synthesized only once and that it can be attached to any

TABLE 1 PCR Primers

\begin{tabular}{ll}
\hline Primer & Sequence $\left(5^{\prime} \rightarrow 3^{\prime}\right)$ \\
\hline$A^{\text {cerbb-2 }}$ & AGAGCCAGCCCTCTGACGTC \\
$\mathrm{B}^{\mathrm{c}-e r b B-2}$ & CGCCGCCGCCGCCCGGAGGATCCCAAAGAC \\
$\mathrm{A}^{\mathrm{p} 53}$ & GCCACTGACAACCACCCTTA \\
$\mathrm{B}^{\mathrm{p} 53}$ & CGCCGCCGCCGCCCGAGACGACAGGGCTGG \\
$\mathrm{C}$ & CGCCCGCCGCGCGCCGCGCCCGTCCCGCCGCCGCCCGCCGCCGCCGCCCG \\
\hline
\end{tabular}

The linker sequence in primers $B$ and $C$ is underlined.

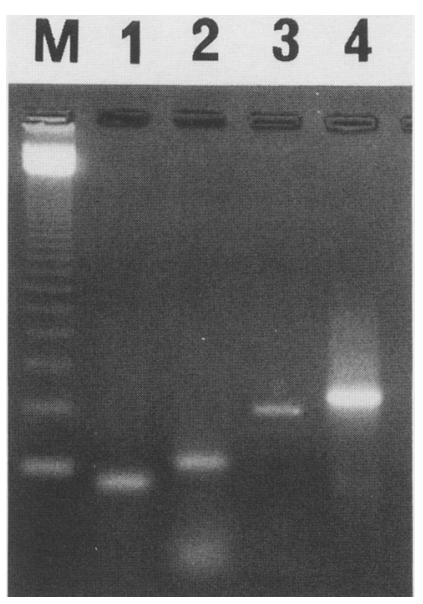

FIGURE 2 Ethidium bromide staining of amplified DNA fragments size separated on a $2.5 \%$ (wt/vol) agarose gel. (Lanes 1 and 3) PCR products of a 84-bp transmembrane fragment of the human c-erbB-2 proto-oncogene and a 230-bp fragment containing exon 6 of the human p53 gene, respectively, amplified by primers $A$ and $B$. The actual size of both fragments is $15 \mathrm{bp}$ longer because of the linker sequence of primer B. PCR was carried out on $100 \mathrm{ng}$ of total genomic DNA in a buffer containing $10 \mathrm{~mm}$ Tris $\cdot \mathrm{HCl}, \mathrm{pH} 8.4,50 \mathrm{mM} \mathrm{KCl}$, $2.5 \mathrm{mM} \mathrm{MgCl}_{2}, 0.2 \mathrm{mM}$ of each dNTP, 1 unit of Taq polymerase (Perkin-Elmer Cetus), and 25 pmoles of each PCR primer in a total volume of $50 \mu$ l. Amplification was performed in 35 cycles of $94^{\circ} \mathrm{C}(30 \mathrm{sec}), 55^{\circ} \mathrm{C}(30 \mathrm{sec})$, and $74^{\circ} \mathrm{C}$ ( $1 \mathrm{~min}$ ) on a Hybaid thermal cycler. (Lanes 2 and 4) GC-clamped PCR products of the c-erbB-2 and p53 gene fragments generated by two consecutive amplifications, respectively. The first round of amplification was performed with 25 pmoles of each primer $A$ and $B$ as described above, only for 20 cycles. One microliter of PCR product was transferred to a second round of amplification with primers $A$ and $C$ using conditions as described above for 35 cycles. The size marker is a 123-bp DNA ladder (GIBCO BRL). Primers were synthesized on a Cyclone DNA synthesizer (Biosearch Inc.), extracted from the columns, ethanol-precipitated, and used for PCR without further gel or HPLC purification.

DNA fragment that has been amplified by primers in which one contains the 15-bp linker sequence.

\section{ACKNOWLEDGMENTS}

The author wishes to thank Siegina G. Evers for technical assistance and Sjoerd Rodenhuis and Wolter J. Mooi for critical reading of the manuscript. This work was supported by grant NKI 91-08 from the Dutch Cancer Society NKB. 


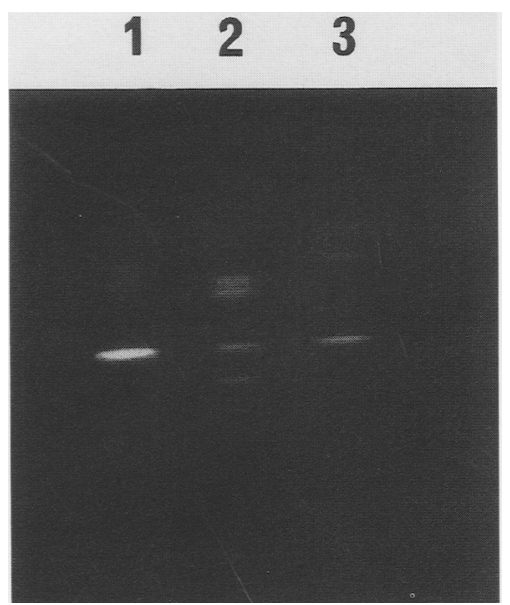

FIGURE 3 DGGE analysis of GC-clamped exon 6 fragments of the p53 gene. Electrophoresis was performed on an $8 \%$ polyacrylamide gel containing a $30-55 \%$ linear denaturing gradient at $150 \mathrm{~V}$ for $5.5 \mathrm{hr}$ at $60^{\circ} \mathrm{C}$. (Lane 1) wild type; (lanes 2 and 3 ) mutated fragments. Visualization of the DNA fragments was performed by ethidium bromide staining. DGGE equipment was purchased from CBS Scientific Inc. (Del Mar, California).

\section{REFERENCES}

1. Rossiter, B.J. and C.T. Caskey. 1990. Molecular scanning methods of mutation detection. J. Biol. Chem. 265: 12753-12756.

2. Fischer, S.G. and L.S. Lerman. 1983. DNA fragments differing by single-base-pair substitutions are separated in denaturing gradient gel: Correspondence with melting theory. Proc. Natl. Acad. Sci. 80: 1579 1583.

3. Abrams, E.S., S.E. Murdaugh, and L.S. Lerman. 1990. Comprehensive detection of single base changes in human genomic DNA using denaturing gradient gel electrophoresis and a GC-clamp. Genomics 7: 463-475.

4. Higuchi, M., S.E. Antonorakis, L. Kasch, J. Oldenburg, E. Economou-Petersen, K. Olek, M. Arai, H. Inaba, and H.H. Kazazian. 1991. Molecular characterization of mild to moderate hemophilia A: Detection of the mutation in 25 of 29 patients by denaturing gradient gel electrophoresis. Proc. Natl. Acad. Sci. 88: 8307-8311.

5. Sheffield, V.C., D.R. Cox, L.S. Lerman, and R.M. Myers. 1989. Attachment of a 40base-pair G + C-rich sequence (GC-clamp) to genomic DNA fragments by the polymerase chain reaction results in improved detection of single-base changes. Proc. Natl. Acad. Sci. 86: 232-236.

6. Myers, R.M., S.G. Fischer, L.S. Lerman, and T. Maniatis. 1985 . Nearly all single base substitutions in DNA fragments joined to a GC-clamp can be detected by denatur- ing gradient gel electrophoresis. Nucleic Acids Res. 13: 3131-3145.

7. Saiki, R.K., D.H. Gelfand, S. Stoffel, S.J. Scharf, R. Higuchi, G.T. Horn, K.B. Mullis, and H.A. Erlich. 1988. Primer-directed enzymatic amplification of DNA with a thermostable DNA polymerase. Science 239: 487-491.

8. Coussens, L., T.L. Yang-Feng, Y.-C. Liao, E. Chen, A. Gray, J. McGrath, P.H. Seeburg, T.A. Libermann, J. Schlessinger, U. Francke, A. Levinson, and A. Ullrich. 1985. Tyrosine kinase receptor with extensive homolgy to EGF receptor shares chromosomal localisation with neu oncogene. Science 230: 1132-1139.

9. Buchman, V.L., P.M. Chumakov, N.N. Ninkina, O.P. Samarina, and G.P. Georgiev. 1988. A variation in the structure of the protein-coding region of the human p53 gene. Gene 70: 245-252.

Received May 8, 1992; accepted May 29, 1992. 


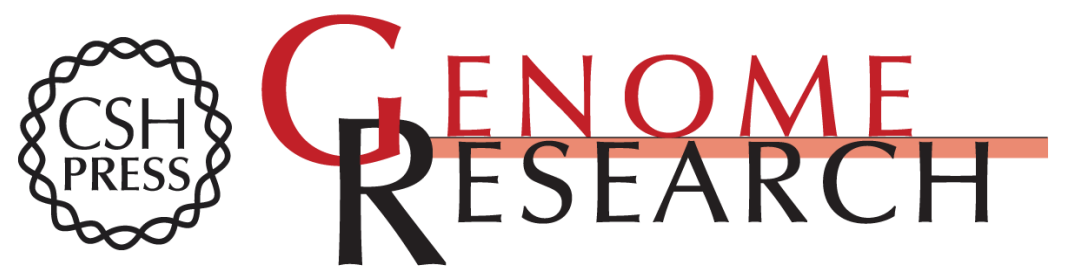

\section{A simple method to attach a universal 50-bp GC-clamp to PCR fragments used for mutation analysis by DGGE.}

B Top

Genome Res. 1992 2: 83-85

Access the most recent version at doi:10.1101/gr.2.1.83

References This article cites 9 articles, 6 of which can be accessed free at:

http://genome.cshlp.org/content/2/1/83.full.html\#ref-list-1

\section{License}

Email Alerting Receive free email alerts when new articles cite this article - sign up in the box at the Service top right corner of the article or click here.

\section{Affordable, Accurate Sequencing.}

To subscribe to Genome Research go to: https://genome.cshlp.org/subscriptions 